\title{
Development of a Standardized Patient Instructor to Teach Functional Assessment and Communication Skills to Medical Students and House Officers
}

\author{
Brent C. Williams, MD, MPH, ${ }^{*}$ Karen E. Hall, MD, PhD, ${ }^{*}$ Mark A. Supiano, MD, ${ }^{* \dagger}$ \\ James T. Fitzgerald, $P h D,{ }^{*+\mathcal{S}}$ and Jeffrey B. Halter, $M D^{* \dagger}$
}

Professional societies have called for increased geriatrics training for all medical students and physicians.

A Geriatrics Standardized Patient Instructor (GSPI) was developed in which learners assess the functional status of a patient preparing for hospital discharge. Standardized patients (SPs) rate learners on functional assessment and communication skills, and provide feedback.

Seventeen SPs were trained. Correlations of ratings by SPs with ratings by three geriatricians of videotaped encounters indicated good reliability (correlation coefficient $=0.69$ and 0.70 for functional assessment and communication skills, respectively). Results from two learner groups illustrated the utility and feasibility of the GSPI. First, 138 house officers in nine specialties experienced the GSPI as a formative evaluation during implementation of new geriatrics curricula. Mean scores \pm standard deviation (on a 100-point scale) for functional assessment and communication skills were $78 \pm 16$ and $86 \pm 11$, respectively. House officers rated the overall experience positively (mean rating $(1=$ poor, $5=$ excellent) $3.9 \pm 0.8)$. Second, 171 first-year medical students (M1 s) encountered the GSPI as part of an intense, multimodal educational intervention. Mean scores on functional assessment and communication skills were $93 \pm 10$ and $93 \pm 7$, respectively. Mean overall rating of the experience by $\mathrm{M} 1 \mathrm{~s}$ was $4.1 \pm 0.8$.

After demonstrated success as a teaching tool in these two groups of learners, the GSPI has been successfully used

From the * Department of Internal Medicine, Divisions of Geriatric Medicine and General Medicine, ${ }^{\dagger}$ Geriatric Research, Education, and Clinical Center, Ann Arbor Veterans Affairs Healthcare System, Ann Arbor, Michigan; ${ }^{\ddagger}$ Department of Internal Medicine, Division of Geriatric Medicine, University of Utah Health System, Department of Veterans Affairs Salt Lake City Geriatric Research, Education, and Clinical Center, University of Utah Center on Aging, Salt Lake City, Utah; and ${ }^{\S}$ Department of Medical Education, University of Michigan Healthcare System, Ann Arbor, Michigan.

Portions of the results reported in this paper were presented at the 2004 and 2006 Annual Scientific Meetings of the American Geriatrics Society, Las Vegas, Nevada, May 18, 2004, and Chicago, IL, May 4, 2006.

Address correspondence to Brent C. Williams, MD, MPH, $300 \mathrm{~N}$. Ingalls Building, Room 7E18, Ann Arbor, MI 48109. E-mail: bwilliam@umich.edu DOI: $10.1111 / \mathrm{j} .1532-5415.2006 .00857 . x$ with second- and third-year (M3) medical students and house officers from a total of 12 specialties and incorporated into multistation Objective Standardized Clinical Examination exercises for incoming house officers and M3 s.

Unlike existing diagnosis-oriented SPs, the GSPI can be used to assess and teach geriatrics skills to physician learners across disciplines and levels of training. J Am Geriatr Soc 54:1447-1452, 2006.

Key words: geriatric assessment; medical education; standardized patient; aged; geriatric; functional assessment; older patient

Cpecialists and primary care physicians face a dramatic $\checkmark$ increase in the percentage of older patients in their practice. Although increasing geriatrics content in medical curricula at all educational levels has been a national goal, the increase is occurring slowly. ${ }^{1}$ Geriatrics training is rare in subspecialty fellowships and surgical residencies and has been identified as a particular need by the specialties themselves. ${ }^{2}$ Initiatives to increase geriatric knowledge in the surgical specialties emphasize the importance of incorporating knowledge and skills training in the care of older patients into residency and fellowship programs of nonprimary care specialties, ${ }^{3}$ but before specialist training, negative attitudes toward geriatrics appear to be set early in medical school training. ${ }^{4}$ This may be due to a lack of integration of geriatric issues into the medical curriculum. ${ }^{5}$ Elective experiences in geriatrics have historically included only a minority of the medical student class. ${ }^{6,7}$ Recent studies indicate a significant lack of knowledge among medical students concerning the special needs and functional impairments of geriatric patients. ${ }^{8}$ In 2004, fewer than half of medical students reported receiving geriatrics training in all 4 years of medical school. ${ }^{9}$

To address these geriatrics training needs, a Geriatrics Standardized Patient Instructor (GSPI) was developed to train and evaluate student and physician learner proficiency in core assessment and communication skills relevant to the 
care of older patients. The goal was to create a skillsbased educational experience that could be used to educate and evaluate learners at undergraduate, graduate, and postgraduate levels of training and in different specialties.

\section{METHODS}

\section{Conceptual Design of the GSPI}

In 2002, a planning committee consisting of geriatricians (MS, BW), a psychometrician-educator (JF), and administrative personnel from the Standardized Patient (SP) program at the University of Michigan reviewed existing SPs on geriatric topics described in the literature or available from other institutions. Most focused on the identification and management of specific diseases and syndromes ${ }^{10,11}$ or communication skills only. ${ }^{12,13}$ Most were designed to be used at a single stage in training (e.g., medical school clerkship) and were usually designed for primary care trainees. Longitudinal cases were identified that are more suited to geriatrics inpatient units or geriatrics fellowship programs. ${ }^{14}$ Therefore, the planning committee decided to develop an SP that would be relevant to a wide range of levels and types of learners and that would focus on basic skills relevant to caring for patients with any chronic illness or functional impairment. The emphasis of the GSPI was on the performance of standard, validated assessment maneuvers that would be useful in an outpatient or inpatient setting; that would identify cognitive, affective, and functional impairments common in older patients; and that have been recommended for all physicians. ${ }^{15}$ The exercise was designed to be used as a formative experience, through which learners could receive training with immediate performance feedback (the GSPI), or an evaluative tool as one component of an Objective Standardized Clinical Examination (OSCE).

The GSPI was designed to:

Simulate an inpatient about to be discharged from the hospital or emergency department who has multiple deficits of cognition and function

Include assessment of activities of daily living (ADLs), instrumental activities of daily living (IADLs), cognition, affect, gait, and continence,

Assess learners' communication skills

Focus on the use and interpretation of rapid, validated screening tools

Be instructional in nature

Use the same rating scales for all levels and types of learners

Require a maximum of 15 minutes for the encounter for all learners and less than 1 hour for house officers to complete the entire exercise including feedback and debriefing

Faculty from the medical school and two of the departments targeted for the intervention among house officers-emergency medicine and obstetrics and gynecologyreviewed the content and design of the GSPI for relevance and applicability to their disciplines. The University of Michigan institutional review board approved the study.

\section{SP Training and Pilot Testing}

During the summer and fall of 2002, five SPs were trained. All were female geriatric-aged volunteers with prior experience as SP instructors for a different clinical scenario. None were professional actors. The SPs received a total of 6 hours of training in two intensive sessions, followed by a 2hour debriefing by staff from the Standardized Patient Program and three geriatric medicine faculty (KH, BW, MS). Training documents described behavior and verbal responses during the encounter, scoring of checklists, and content of feedback to the learner. Encounters were pilot tested on three geriatric medicine fellows and 10 medical students selected from the second through the fourth years. At least one of the authors reviewed videotapes of at least three encounters for each SP for consistency. After the initial cohort of SPs was trained in January 2003, an additional 12 SPs (10 female, 2 male) were trained by February 2003.

\section{SP Encounter}

The SP scenario involves an older patient about to be discharged from the emergency department or hospital. The encounter is essentially identical for all learners, differing only in the description of the main condition for which the patient was seen or hospitalized. For example, for emergency department house officers, the patient was brought in for dizziness and was being discharged after an overnight stay and negative cardiac evaluation, whereas for rheumatology house officers, the patient was being discharged after a hospitalization for fever of unknown origin with a diagnosis of temporal arthritis. At the onset of the encounter, the learner had just finished making rounds on the patient and preparing his or her discharge orders. A nurse notified the learner that the patient's daughter would not be able to take the patient home because "We just can't handle him/her at home," and will be unavailable for at least 6 hours. The learner is directed to interview the patient and apply standardized assessment tools to identify functional impairments. As the learner enters the room, the patient is seated in a chair with a radio playing loudly and a pair of glasses on a nearby table. Impairments demonstrated by the patients include impairments in ADLs (e.g., use of downstairs bathroom to take sponge baths due to fear of climbing stairs, errors in dressing with buttons done incorrectly), impairments in IADLs (e.g., daughter assists with grocery shopping, finances, and transportation), mild cognitive impairment, and a history of falls. The SPs were instructed not to demonstrate delirium or depressed affect.

A Learner Instruction Packet was prepared for the learners, to communicate behavioral expectations for the encounter, provide instructional content, and emphasize the educational rather than the evaluative nature of the encounter. ${ }^{16}$ The packet included a one-page description of the case history and instructions on how to initiate and conclude the encounter, a list of assessment domains to be tested, a description of the assessment tools required to test each domain and their clinical applications, and tips on how to communicate with older patients. A pocket card with brief instructions for the assessments was also prepared. Validated assessment tools described included a list of ADLs and IADLs, ${ }^{17}$ Mini-Mental State Examination, ${ }^{18}$ 
Mini-Cog, ${ }^{19}$ Timed Up and Go (TUG) Test, ${ }^{20}$ and the twoquestion depression screener. ${ }^{21}$

\section{Measurements}

Immediately after the encounter, the SP rated learners using a 32 -item checklist with 3-point rating scales. Twenty-three items related to functional assessment and included measures of ADLs and IADLs (12 items), one item each on falls and continence $(1=$ not asked, $2=$ asked, $3=$ asked in detail; the continence item was not included on the medical student rating checklist), two items on performing the TUG $(1$ = needs improvement, $2=$ adequately done, $3=$ skillfully done), seven items on the Mini-Cog ${ }^{19}$ and 2-question depression screener ${ }^{21}(1=$ not done, $2=$ needs improvement, 3 =done), and nine items on communication skills (e.g., addressed patient by his/her last name, treated the patient with respect; 1 = needs improvement, 2 = adequately done, 3 = skillfully done).

To calculate performance scores, SP learner ratings were dichotomized to emphasize the presence or absence of each behavior. This reflected the fact that the primary purpose of the encounter was to teach learners to screen for functional impairment rather than perform a detailed assessment, as a geriatrician might make. For example, it was desired that learners would inquire about each of six ADLs, rather than not inquiring at all, so scores were dichotomized as not asked versus asked/asked in detail. Functional assessment and communication items were summed separately and standardized to 100-point scales for an overall score in each domain.

After the encounter, learners completed a 17-item written survey evaluating the experience. All item responses were on a 5 -point scale, for example, measuring the value of having immediate SP feedback $(1=$ strongly disagree to $5=$ strongly agree), comfort level with functional assessment before and after the experience $(1=$ very anxious to $5=$ very comfortable $)$, and the overall experience $(1=$ poor to $5=$ excellent).

\section{Reliability and Validity}

To achieve content validity, geriatricians and nongeriatrician specialists from emergency medicine and gynecology developed the GSPI. To measure the reliability of SP learner ratings, three geriatricians independently reviewed videotapes of 18 encounters between house officers and the first five trained SPs. Mean geriatrician scores were compared with SP ratings by examining overall means and correlation coefficients.

\section{Instructional Feedback to Learners}

After rating the learner, the SP provided feedback on functional assessment and communication skills. Learners then met as a group with a geriatric medicine faculty and, in the case of the house officers, a faculty member from that specialty in a debriefing session to discuss clinical applications of the assessment tools.

\section{Applications}

To illustrate the range of applications of the GSPI, results and responses from two learner groups-house officers undergoing formative evaluation, and first-year medical students (M1 s) participating in a multimodal educational intervention - are described.

\section{House Officers}

One hundred thirty-eight house officers in nine disciplines encountered the GSPI between February 2003 and June 2005 as part of an institution-wide initiative to develop geriatrics curricula among surgical specialties and medical subspecialties. In each discipline, one faculty member was trained in geriatrics and teaching and developed multiple lectures and clinical teaching experiences related to the care of older patients for the house officer program. In most disciplines, the GSPI was implemented within a few weeks of an introductory lecture on geriatric assessment. At the lecture, the Learner Instruction Packets were distributed with instructions to review then before the SP encounter. Learners were provided with pocket cards at the time of the encounter. Disciplines included anesthesiology $(n=43)$, emergency medicine $(n=26)$, physical medicine and rehabilitation $(\mathrm{n}=24)$, hematology/oncology $(\mathrm{n}=17)$, obstetrics/gynecology $(n=7)$, endocrinology $(n=7)$, orthopedic surgery $(\mathrm{n}=5)$, rheumatology $(\mathrm{n}=5)$, and gastroenterology $(\mathrm{n}=4)$.

In anesthesiology, the supervising faculty member requested that the learner rating checklist be revised substantially, to exclude items on gait assessment and include items on reviewing medications and assessing decision-making capacity.

For all house officers, the entire learning experience (orientation, encounter, SP feedback, and faculty-led debriefing) took 1 hour. Learners were given up to 15 minutes for the encounter itself.

\section{First-Year Medical Students}

A total of $171 \mathrm{M} 1 \mathrm{~s}$ experienced the GSPI as part of a multimodal educational intervention on functional assessment of older patients during April and May 2003. Students attended a 90-minute seminar at which the rationale and methods for functional assessment were reviewed, including each of the assessment tools used in the GSPI. Students received the Learner Instruction Packet, which included detailed instructions on completing the GSPI, and were encouraged to review examples of successful encounters on videotape. Finally, pocket cards containing instructions on the assessment maneuvers were provided and brought into the GSPI encounter by the students.

After the seminar, learners completed the GSPI encounter and received immediate feedback from the SP. Learners were permitted a maximum of 15 minutes for the encounter. All sessions were conducted in the University of Michigan Learning Resource Center and videotaped.

\section{RESULTS}

\section{Reliability and Validity}

For the 18 GSPI encounters with house officers rated by geriatricians and SPs, mean geriatrician standardized scores were similar to SP scores (Table 1). Mean scores \pm standard deviation for functional assessment items and communication items were similar between the SPs and geriatricians $(81 \pm 11$ and $77 \pm 11$ for functional assessment, $88 \pm 10$ 
Table 1. Comparison of Learner Performance Scores* of Standardized Patients and Geriatrics Faculty for 18 House Officers

\begin{tabular}{lccc}
\hline & \multicolumn{2}{c}{ Standardized Patients } & Geriatrics Faculty \\
\cline { 2 - 3 } \multicolumn{1}{c}{ Item } & \multicolumn{1}{c}{ Mean \pm Standard Deviation } & Correlation Coefficient \\
\cline { 2 - 3 } Functional assessment (23 items) & $81.0 \pm 10.8$ & $76.9 \pm 10.9$ & 0.69 \\
Communication (8 items) & $88.2 \pm 10.0$ & $88.2 \pm 8.7$ & 0.70 \\
\hline
\end{tabular}

${ }^{*}$ Scores represent the fraction of items for which a behavior was present, scaled to range from 0-100.

and $88 \pm 9$ for communication skills, respectively). Correlation coefficients for the two sets of scores for functional assessment and communication skills were 0.69 and 0.70 , respectively (Table 1 ).

Following the reliability/validity analyses, two checklist items were modified. First, the rating scales for the two TUG items were changed from needs improvement/adequately done/skillfully done to not done/needs improvement/done when it was observed that a few learners did not do the TUG at all. Second, one communication item that was conditional on inadequate performance on other items (Altered behavior to accommodate impaired hearing (if the learner did not speak in a low-pitched voice)) was dropped after the SPs reported difficulty in completing this item, resulting in a 31-item checklist for house officers and a 30-item checklist for medical students (which lacked the continence item).

\section{Learner Performance}

Descriptions of SP ratings of house officer performance include the 95 house officers from disciplines other than anesthesiology (who used an alternate checklist). Mean scores of house officers undergoing formative evaluation were $78 \pm 16$ and $87 \pm 11$ for functional assessment and communication skills, respectively (Table 2). The percentage of learners who performed individual tasks varied across tasks. For example, only $48 \%$ of house officers inquired about grooming, and 98\% inquired about grocery shopping. Similar patterns were observed in individual house officer programs (data not shown).

For M1 s experiencing the GSPI as part of a detailed, multimodal educational intervention with demonstrations, performance scores were expectedly high. Mean scores for functional assessment and communication skills were $92 \pm 10$ and $93 \pm 7$, respectively (Table 2 ). The percentage of learners performing individual tasks was above $90 \%$ for 23 of the 31 items on the checklist (Table 2).

House officers and M1 s rated the overall exercise and specific aspects of the exercise highly and reported significant increases in comfort with performing functional assessments as a result of the exercise (Table 3 ). Both groups of learners perceived significant increases in confidence in performing functional assessments on older patients. House officers and M1 s also rated the overall experience highly, with mean overall ratings of $3.9 \pm 0.8$ and $4.1 \pm 0.8$, respectively, on a 5 -point scale (Table 3 ). Overall ratings were relatively consistent between house officer disciplines, although the number of house officers in each discipline was too small for statistical comparisons.
Table 2. Learner Performance on Geriatrics Standardized Patient

\begin{tabular}{|c|c|c|}
\hline Domain & $\begin{array}{l}\text { House } \\
\text { Officers } \\
\left(n=95^{*}\right)\end{array}$ & $\begin{array}{l}\text { Medical } \\
\text { Students } \\
(n=171)\end{array}$ \\
\hline $\begin{array}{l}\text { Overall functional assessment score, } \\
\text { mean } \pm \mathrm{SD}^{\dagger}\end{array}$ & $78 \pm 16$ & $92 \pm 10$ \\
\hline \multicolumn{3}{|l|}{ Activities of daily living, $\%$} \\
\hline Eating & 66 & 92 \\
\hline Transferring from bed to chair & 63 & 84 \\
\hline Going to the toilet & 62 & 88 \\
\hline Bathing & 67 & 95 \\
\hline Dressing & 74 & 95 \\
\hline Grooming & 48 & 79 \\
\hline Medication management & 73 & 91 \\
\hline Grocery shopping & 98 & 98 \\
\hline Food preparation & 83 & 95 \\
\hline Using the telephone & 44 & 81 \\
\hline Driving & 68 & 84 \\
\hline Handling own finances & 64 & 87 \\
\hline $\begin{array}{l}\text { Asked about falls in the } \\
\text { previous year, \% }{ }^{\ddagger}\end{array}$ & 85 & 74 \\
\hline Urinary incontinence, $\%$ & 76 & $N A^{\S}$ \\
\hline $\begin{array}{l}\text { Gait assessment (Timed Up } \\
\text { and Go, } 2 \text { items), \%॥ }\end{array}$ & 76 & 99 \\
\hline \multicolumn{3}{|l|}{ Cognition and depression, \% } \\
\hline Mini-Cog (5 items) ${ }^{\|}$ & 95 & 88 \\
\hline $\begin{array}{l}\text { 2-question depression } \\
\text { screener ( } 2 \text { items) } \|\end{array}$ & 90 & 98 \\
\hline $\begin{array}{l}\text { Overall communication score, } \\
\text { mean } \pm \mathrm{SD}^{\dagger}\end{array}$ & $87 \pm 11$ & $93 \pm 7$ \\
\hline \multicolumn{3}{|l|}{ Individual items, \% } \\
\hline Addressed patient by last name & 90 & 93 \\
\hline Allowed sufficient time to answer & 99 & 100 \\
\hline Turned off radio & 81 & 98 \\
\hline Aided with glasses & 45 & 49 \\
\hline Treated with respect & 95 & 100 \\
\hline
\end{tabular}

Note: House officers completed the encounter up to several weeks after an introductory lecture. Medical students completed the encounter immediately after a learning exercise that included detailed instruction and videotaped demonstrations of the encounter. Performance results of the two groups are therefore not comparable.

* Excludes anesthesiology house officers $(n=43)$, who used an alternate checklist. See text for details.

${ }^{\dagger}$ Scores represent the fraction of items for which a behavior was present, scaled to range from $0-100$.

${ }^{\ddagger}$ Percentage of learners who inquired about that item.

$\$^{\$}$ Continence item not included in first-year medical school student exercise.

" Percentage of learners who performed all steps of the assessment maneuver.

"Percentage of learners who performed the task.

$\mathrm{SD}=$ standard deviation 
House Officers

$(\mathrm{n}=122 *)$

Mean Rating \pm Standard Deviation

Item

The objectives and expectations for this session were clear. ${ }^{\dagger}$

It was helpful to receive feedback immediately after the interviewing session. ${ }^{\dagger}$

Before this exercise, I felt _ about performing an assessment of an older patient. ${ }^{\ddagger}$

After this exercise, I felt _ about performing an assessment of an older patient. ${ }^{\ddagger}$

Overall this session was

$\begin{array}{ll}4.2 \pm 0.9 & 3.6 \pm 1.0 \\ 4.6 \pm 0.8 & 4.7 \pm 0.5 \\ 3.6 \pm 0.9 & 3.3 \pm 0.9 \\ 4.1 \pm 0.7 \S & 4.2 \pm 0.6 \S \\ 3.9 \pm 0.8 & 4.1 \pm 0.8\end{array}$

\footnotetext{
* Excludes 16 house officers for whom data were incomplete.

$\dagger 1=$ strongly disagree to $5=$ strongly agree.

$\ddagger 1=$ very anxious to $5=$ very comfortable.

${ }^{\S} P<.01$ compared with pre-SP rating.

$\| 1=$ poor to $5=$ excellent.
}

\section{DISCUSSION}

The GSPI was developed to help meet educational and evaluation needs in geriatrics for medical students and house officers at all levels of training and across a wide variety of disciplines. Specifically, the GSPI was intended to develop learners' skills in functional assessment and communication while fostering their beliefs that rapid screening for function impairment is feasible in a variety of clinical settings and specialties.

Unlike previous geriatrics SPs, the GSPI focuses on generic (functional assessment and communication) rather than disease-specific skills to provide a variety of levels and types of physicians with a meaningful learning experience in geriatrics clinical care. The development methods and performance characteristics of the GSPI demonstrate its validity and reliability and are comparable with those reported for other standardized patients. ${ }^{22}$ In the two applications described here, the GSPI was used as a teaching tool. For house officers, who received only brief preparatory instruction, the GSPI was used as a formative feedback experience, providing direct feedback from the SP and a faculty member, along with written learning tools and a pocket card as part of the encounter. House officer performance demonstrated adequate variation and absence of floor and ceiling effects, supporting the usefulness of the GSPI as an instructional method. For M1s, the GSPI was part of a multimodal learning experience that included review of geriatric assessment and communication, detailed review of the assessment instruments, and review of videotapes of "good" and "bad" encounters with the GSPI. The expected high performance of medical students demonstrated the effectiveness of the multimodal learning experience in influencing assessment and communication skills.

Although a single encounter with a standardized patient is unreliable as a measure of an individual learner's skills, the GSPI can provide a reliable "snapshot" of performance in groups of learners, and group-level results can appropriately be used to modify curricula and report performance-based competencies to regulatory bodies.

Medical students and house officers perceived the encounter as educational, enjoyable, and useful. All learners reported significant increases in comfort with performing functional assessment. Based on conversations with learn- ers of many types, it appears that two features were important in making the experience a positive one. First, the use of a laminated pocket card to prompt learners during the geriatrics SP encounter improved performance of tasks and was highly rated by learners. Second, faculty debriefing after the SP interview appeared to improve understanding of the use of the assessment tools. Faculty debriefing also appeared to improve attitudes toward the feasibility and utility of geriatric functional assessment as judged by learner comments during the debriefing sessions. For house officers, especially, discipline-specific faculty provided a role model and practical tips that increased learners' enthusiasm for incorporating functional assessment into routine clinical practice.

Training in the care of older patients has increased substantially in medical schools in recent years. In 2001, although only $8 \%$ of allopathic medical schools reported a separate required course in geriatrics, $54 \%$ offered a separate elective course in geriatrics. ${ }^{1,9}$ For house officers, participants in the American Geriatrics Society-Hartford Foundation Geriatrics for Subspecialists Project recently identified development and testing of functional assessment techniques that are feasible and valid for use in surgical specialties and non-primary care medical specialties as a critical area for research. ${ }^{2}$ This group, comprising more than 60 individuals representing surgical specialties, emergency medicine, geriatrics, funding agencies including the National Institutes of Health, National Institute on Aging, the RAND Corporation, and the American Geriatrics Society, has also recommended that surgical specialists routinely use the same assessment tools used in the GSPI in the diagnosis and treatment of older patients. ${ }^{3}$ In the past few years, the John A. Hartford Foundation and the Donald W. Reynolds Foundations have launched new initiatives to enhance medical students' and house officers' abilities to assess and manage older patients. ${ }^{23}$ Improved methods of teaching and measuring medical students' and house officers' performance of core skills in geriatrics will help support expanded training in geriatrics.

Based on the early success and acceptability of the GSPI as a learning experience, the medical school at the University of Michigan now routinely incorporates this patient encounter as a learning experience for second-year medical students, and as an evaluative exercise as part of a third- 
year medical student multistation OSCE. In an analogous fashion, the Office of Graduate Medical Education has used the Geriatrics Standardized Patient as a learning experience for house officers from 12 non-primary care disciplines and as an evaluative exercise as a station in an OSCE administered to all incoming house officers at the University of Michigan. (It is omitted from the OSCE for incoming pediatrics residents.)

To help disseminate the methods and content of the GSPI, the Learner Packet, containing instructional materials, is available through the Portal of Online Geriatrics-Education, ${ }^{24}$ along with other tools and resources for teaching geriatrics clinical skills to physician learners and assessing how well they are learned.

\section{ACKNOWLEDGMENTS}

The authors thank the following faculty for their assistance in the development and review of the GSPI: Jocelyn Wiggins, MD, Robert Hogikyan, MD, and Katherine Supiano, MS, CSW (Division of Geriatric Medicine, Department of Internal Medicine); Helen Kales, MD (Department of Psychiatry); Eve Losman, MD (Department of Emergency Medicine); and Pamela Davies, MD (Department of Obstetrics and Gynecology). The authors would also like to thank the SPs and staff of the Learning Resource Center at the University of Michigan.

Financial Disclosure: Supported in part by a grant from the Donald W. Reynolds Foundation.

Author Contributions: Brent C. Williams and Karen E. Hall: study concept and design, acquisition of subjects and data, interpretation of data, and preparation of manuscript. Mark A. Supiano: study concept and design, acquisition of subjects and data, interpretation of data, and final edits to manuscript. James T. Fitzgerald: study concept and design, analysis of data, and final edits to manuscript. Jeffrey B. Halter: study concept and design, acquisition of subjects and data, and final edits to manuscript.

Sponsor's Role: The Donald W. Reynolds Foundation did not participate in the design, methods, subject recruitment, data collection or analysis, or preparation of this manuscript.

\section{REFERENCES}

1. Warshaw GA, Bragg EJ, Shaull R et al. Academic geriatric programs in US allopathic and osteopathic medical schools. JAMA 2002;288:2313-2319.

2. Solomon DH, Burton JR, Lundebjerg NE et al. The new frontier: Increasing geriatrics expertise in surgical and medical specialties. J Am Geriatr Soc 2000;48:702-704.

3. Katz PR, Grossberg GT, Potter JF et al., eds. Geriatrics, Syllabus for Specialists. New York: American Geriatrics Society, 2002.
4. Fitzgerald JT, Wray LA, Halter JB et al. Relating medical students' knowledge, attitudes, and experience to an interest in geriatric medicine. Gerontologist 2003;43:849-855.

5. Varner KS, ed. American Association of Medical Colleges Curriculum Directory, 27th Ed. Washington, DC: American Association of Medical Colleges, 1998.

6. Barry PP. Geriatric clinical training in medical schools. Am J Med 1994; 97(Suppl 4A):8S-9S.

7. Fields SD, Jutagir R, Adelman RD et al. Geriatric education. Part I. Efficacy of a mandatory clinical rotation for fourth year medical students. J Am Geriatr Soc 1992;40:964-969.

8. Lee M, Wilkerson L, Reuben DB et al. Development and validation of a geriatric knowledge test for medical students. J Am Geriatr Soc 2004;52:983988.

9. Warshaw GA, Bragg EJ. ADGAP Longitudinal Study on Training and Practice in Geriatric Medicine, 2005. Table 5.4 [on-line]. Available at www.adgapstudy.uc.edu Accessed October 31, 2005.

10. Biernat K, Simpson D, Duthie E Jr. et al. Primary care residents self assessment skills in dementia. Adv Health Sci Educ Theory Pract 2003;8:105110 .

11. Nagoshi M, Williams S, Kasuya R et al. Using standardized patients to assess the geriatrics medicine skills of medical students, internal medicine residents, and geriatric fellows. Acad Med 2004;79:698-702.

12. Haist SA, Wilson JF, Pursley HG et al. Domestic violence: Increasing knowledge and improving skills with a four-hour workshop using standardized patients. Acad Med 2003;78(Suppl 10):S24-S26.

13. Brown A, Anderson D, Szerlip HM. Using standardized patients to teach disease management skills to preclinical students: A pilot project. Teach Learn Med 2003;15:84-87.

14. Karani R, Callahan EH, Thomas DC. An unfolding case with a linked OSCE. A curriculum in inpatient geriatric medicine. Acad Med 2002;77:938.

15. Core competencies for the care of older patients. Recommendations of the American Geriatrics Society. The Education Committee Writing Group of the American Geriatrics Society. Acad Med 2000;75:252-255.

16. Hall KE, Supiano MA, Williams BC. Geriatric Functional Assessment Standardized Patient Instructor: Medical Student Manual. Portal of Geriatrics Online Education (POGOe) [on-line]. Available at www.pogoe.org Accessed May 9, 2006.

17. Moore AA, Siu AL. Screening for common problems in ambulatory elderly: Clinical confirmation of a screening instrument. Am J Med 1996;100:440.

18. Folstein MF, Folstein SE, McHugh PR. 'Mini-mental state'. A practical method for grading the cognitive state of patients for the clinician. J Psych Res 1975;12:189-198.

19. Borson S, Scanlan JM, Chen P et al. The mini-cog as a screen for dementia: Validation in a population-based sample. J Am Geriatr Soc 2003;51:14511454.

20. Pofsiadlo D, Richardson S. The timed 'Up and Go': A test of basic functional mobility for frail elderly persons. J Am Geriatr Soc 1991;39:142-148.

21. Whooley MA, Avins AL, Miranda J et al. Case-finding instruments for depression. Two questions are as good as many. J Gen Intern Med 1997;12:439_ 445.

22. Van der Vleuten CPM, Swanson DB. Assessment of clinical skills with standardized patients: State of the art. Teach Learn Med 1990;2:58-76.

23. Warshaw GA, Bragg EJ. Medical student training in geriatrics at the beginning of the 21st century. ADGAP Longitudinal Study of Training and Practice in Geriatric Medicine. Training and Practice Update 2003;1: 1-11. Available at www.adgapstudy.uc.edu/pdf/October2003.pdf Accessed October 31, 2005.

24. Portal of Geriatric Online Education [on-line]. Available at www.pogoe.org Accessed May 23, 2006. 